\title{
From Hierarchy of the Levels of Theoretical Inquiry to Full Type 2 Fuzzy System Models
}

\section{Burhan Türkşen I',2*}

${ }^{1}$ Department of Industrial Engineering, TOBB-Economy and Technology University, Sögütözü 06560, Ankara, Turkey

${ }^{2}$ Director-Knowledge Intelligence Systems Laboratory, Department of Mechanical \& Industrial Engineering, University of Toronto, Toronto, Ontario, M5S 3G8, Canada

\begin{abstract}
We first present a brief review of the essentials fuzzy system models: Namely (1) Zadeh's rule base model, (2) Takagi and Surgeon's model which is partly a rule base and partly a regression function and (3) Türkşen fuzzy regression functions where fuzzy regression functions correspond to each fuzzy rule. Next we review the well-known FCM algorithm which lets one to extract Type 1 membership values from a given data set for the development of Type 1 fuzzy system models as a foundation for the development of Full Type 2 fuzzy system models. For this purpose, we provide an algorithm which lets one to generate Full Type 2 membership value distributions for a development of second order fuzzy system models with our proposed second order data analysis. If required one can generate Full Type 3 . Full Type $\mathrm{n}$ fuzzy system models with an iterative execution of our algorithm. We present our application results graphically for TD_Stockprice data with respect to two validity indeces, namely: 1) Çelikyılmaz-Türkşen and 2) Bezdek indeces.
\end{abstract}

Keywords: Ontology,Computing,Stockprice,

\section{Fuzzy Theory}

After Zadeh [1] introduction of Fuzzy Logic and Fuzzy Sets, a vast volume of literature appeared about fuzzy logic and Fuzzy System Modeling (FSM). There are at least two advantages of FSM that attracts researchers: (i) its power of linguistic explanation with the resulting ease of understanding, and (ii) its tolerance to imprecise data which provides flexibility and stability for prediction. But, very few studies, if any, have been devoted to the study of the "Philosophical Grounding of Fuzzy Theory". For this purpose, we briefly review the ontological and epistemological foundations of fuzzy theory. For this purpose, we ask certain essential questions. Our inquiry contains seven steps which are re-stated for Classical theory first and then for Fuzzy theory. Next we suggest some insights to be gained by the grand paradigm shift from the classical to the fuzzy theory. Naturally, this is a limited partial exposition [2].

Ontology lays the ground for the structural statements that are either equivalence for the case of the classical theory or uncertainty intervals for the case of the fuzzy theory. Furthermore we state the Laws of Conservation based on assumptions of existences.

At this level, the inquiry is to be stated as:

- What linguistic expressions can capture our positions to realty in Computing with Words $(\mathrm{CWW})$ ?

- What, Precisiated Natural Language (PNL), expressions can capture our positions to reality?

- What are the basic equivalences or uncertainty intervals and the Laws of Conservation that capture our position to reality?

This theoretical inquiry shown in Table 1 which is stated in general terms and it is captured in terms of the classical theory as shown in Table 2 and in terms of the fuzzy theory in Table 3.

Briefly in the fuzzy theory, every element belongs to a concept class, say $A$, to a partial degree, i.e., $\mu_{A}: X \rightarrow[0,1], \mu_{A}(x)=a \in[0,1], x \in X$, where $\mu_{A}(x)$ is the membership assignment of an element ' $x$ ' to a concept class $\mathrm{A}$ in a proposition. In particular, most of all concepts in the fuzzy theory are assumed to be definable to be true to a degree.

On the ontological level, the positions taken by fuzzy set and logic theorists are shown in Table 3 for the Hierarchy of the Levels of the Theoretical Inquiry. In particular, "a subject, s, in relation, $\mathrm{R}$, to an object, o," schema gives credence to both levels, i.e., the subject and the object interaction. In such a schema, CWW expressions ought to be structured on the basis of meta-linguistic axioms of the Fuzzy Sets and the Logic Theory. These meta-linguistic axioms generate an interval of uncertainty between the Fuzzy Disjunctive and Conjunctive Canonical Forms, FDCF and FCCF [3]. An investigation of the meta-linguistic axioms and the associated combination of concepts for any two fuzzy sets $A$ and $B$ turn out to generate an interval of uncertainty whose boundaries are defined by FDCF and FCCF.

It should be further emphasized that in CWW, the imprecise and varying meanings of linguistic connectives should not be precisiated in an absolute manner. Since in the fuzzy theory, our position is that there is no absolute precisiation of the meaning of words. This provides a framework for the representation of "deterministic uncertainty" in the combination of words and hence in reasoning with them as a foundation for CWW.

\section{Fuzzy system models}

Here first, historically significant fuzzy system model developments are reviewed in order to identify their unique structures and to point out how they differ from each other. Then we show the details of our FULL TYPE 2 Fuzzy System developments with a new algorithm.

\section{Type 1 fuzzy rule base models}

The most commonly applied fuzzy system models are fuzzy rule

*Corresponding author: Burhan Turksen I, Director-Knowledge Intelligence Systems Laboratory, Department of Mechanical \& Industrial Engineering, University of Toronto, Toronto, Ontario, M5S 3G8, Canada, Tel: 416-978-1278; E-mail: turksen@mie.utoronto.ca

Received March 11, 2014; Accepted June 20, 2014; Published June 28, 2014

Citation: Türkşen IB (2014) From Hierarchy of the Levels of Theoretical Inquiry to Full Type 2 Fuzzy System Models. Ind Eng Manage 3: 133. doi: 10.4172/21690316.1000133

Copyright: @ 2014 Türkşen IB. This is an open-access article distributed under the terms of the Creative Commons Attribution License, which permits unrestricted use, distribution, and reproduction in any medium, provided the original author and source are credited. 
Citation: Türkşen IB (2014) From Hierarchy of the Levels of Theoretical Inquiry to Full Type 2 Fuzzy System Models. Ind Eng Manage 3: 133. doi: 10.4172/2169-0316.1000133

Page 2 of 7

\begin{tabular}{|c|c|}
\hline Application Level & $\begin{array}{l}\text { vii. How do people, decision-makers, feel, think, behave, and interact? } \\
\text { How can we provide them with better decision-making tools? } \\
\text { "How can we provide them with a better PNL?" }\end{array}$ \\
\hline $\begin{array}{c}\text { Domain-Specific } \\
\text { Epistemological Level }\end{array}$ & $\begin{array}{l}\text { vi. How do we validate knowledge appropriately in this domain specific field? } \\
\text { What methodological approaches are appropriate to it? } \\
\text { "What ought to be 'Domain specific' PNL for validity of our investigations?" } \\
\text { v. What can we know or hope to learn within this domain-specific field or discipline? } \\
\text { What are the limits or boundaries to it? } \\
\text { "What specific expressions of 'Domain-specific' PNL could and should be used to specify the limits or boundaries of our knowledge?" }\end{array}$ \\
\hline $\begin{array}{c}\text { General Epistemological } \\
\text { Level }\end{array}$ & $\begin{array}{l}\text { iv. How do we validate our knowledge? } \\
\text { How do we know it is true? } \\
\text { What criteria do we use to assess its truth-value? } \\
\text { "What PNL expressions cause the assessment of the truth and knowledge?" } \\
\text { iii. What is our access to the truth and knowledge in general? } \\
\text { Where is knowledge and its truth to be found? } \\
\text { How or from what are they constituted? } \\
\text { "What PNL encoding allows us to assess the truth or knowledge?" }\end{array}$ \\
\hline Ontological Level & $\begin{array}{l}\text { ii. What is our position or relation to that Reality (if we do assume that it exists on level } 1 \text { below)? } \\
\text { "What PNL expressions capture our positions to reality?" } \\
\text { Is there any reality independent or partially independent of us? } \\
\text { Does any absolute truth exist? Does fuzziness exists? }\end{array}$ \\
\hline
\end{tabular}

Table 1: Hierarchy of the levels of theoretical ınquiry and their questions.

\begin{tabular}{|c|c|}
\hline Application Level & vii. Emphasis on mechanistic Super additive systems theory of interactions, relations, equations, etc. \\
\hline $\begin{array}{l}\text { Domain-Specific Epistemological } \\
\text { Level }\end{array}$ & $\begin{array}{l}\text { vi. Validity and methodology dictated by meta-physical theories, e.g., principle of determinism, symmetry, invariance and } \\
\text { randomness. } \\
\text { v. Objective facts and truth accessible, but limited only by, e.g., subjective distortions (introduction of uncertainty). }\end{array}$ \\
\hline General Epistemological Level & $\begin{array}{l}\text { iv. Correspondence theory of Validity which is only Objective. } \\
\text { iii. Objectivist, empiricists, certain. }\end{array}$ \\
\hline Ontological Level & $\begin{array}{l}\text { ii. sRo Cartesian dualism } \\
\text { i. Realism, crisp meaning representation of linguistic } \\
\text { Variables and connectives are defined with two-valued sets and logic theory. Equivalences in "normal forms" together with classical } \\
\quad \text { laws of conservation, as well as formulae for Belief, Plausibility, Probability, etc. }\end{array}$ \\
\hline
\end{tabular}

Table 2: Positions taken by classical set and logic theorists on the hierarchy of the levels of theoretical inquiry.

\begin{tabular}{|c|c|}
\hline Application Level & vii. Emphasis on humanistic Decision and Control Systems that contain highly complex non-linear interactions, relations, equations, etc. \\
\hline $\begin{array}{l}\text { Domain-Specific } \\
\text { Epistemological Level }\end{array}$ & $\begin{array}{l}\text { vi. Validity and methodology dictated by Meta theories of Modal Logics. e.g., principle of non-determinism and overlapping patterns. } \\
\text { v. Subjective and objective facts accessible by perceptions and meaning representation of linguistic terms of linguistic variables, linguistic } \\
\text { quantifiers and linguistic connectives. Principle of uncertainty!! }\end{array}$ \\
\hline $\begin{array}{l}\text { General Epistemological } \\
\text { Level }\end{array}$ & $\begin{array}{l}\text { iv. Correspondence theory of Validity both objective and subjective. } \\
\text { Approximate Reasoning!! } \\
\text { iii. Subjective-objective, experimental and empiricist, e.g., expert and/or fuzzy data mining based. }\end{array}$ \\
\hline Ontological Level & 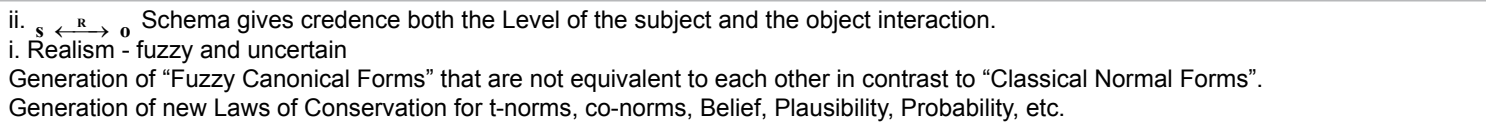 \\
\hline
\end{tabular}

Table 3: Position taken by some of fuzzy set and logic theorists on the hierarchy of the levels of theoretical ınquiry.

bases. Here, we only deal with Multi-Input Single Output (MISO) systems. Generally fuzzy system models represent relationships between the input and output variables which are expressed as a collection of IFTHEN rules that utilize linguistic labels, which are represented with fuzzy sets. The general fuzzy rule base structure which is known as Zadeh- Fuzzy Rule Base, Z-FRB, can be written as follows:

\section{$R: A{ }_{i=1}^{c^{*}} S O$ (IF antecedent ${ }_{\mathrm{i}}$ THEN consequent ${ }_{\mathrm{i}}$ )}

where $c^{*}$ is the number of rules in a rule base either given by experts or it is determined by a fuzzy clustering algorithm such as FCM, FuzzyC-Means [4] or IFC, Improved Fuzzy Clustering [5]. The fuzzy rule base structures determined by various alternatives mainly differ in the representation of the consequents. If the consequent is represented with fuzzy sets then the fuzzy rule base is known as Zadeh [6-8] version which is originally applied by Ebrahim [9] and a modified version is proposed by Sugeno et al. [10] SY-FRB, Whereas, if the consequents are represented with linear equations of input variables, then the rule base structure is the Takagi et al. [11] Fuzzy Rule Base, TS-FRB structure. These are the main models amongst others which we do not review in this paper. In particular Zadeh Fuzzy Rule Bases, Z-FRB can be formalized as:

$$
R: A L_{i=1}^{c^{*}} S\left(\text { IF } x \in X \text { isr } A_{i} \text { THEN } \mathrm{y} \in Y \text { isr } B_{i}\right)
$$

In general, let $n v$ be the number of selected input variables in the system. Then, the multidimensional antecedent, $x$, can be defined as $x=\left(x_{1}, x_{2}, \ldots, x_{n v}\right)$, where $x_{j}$ is the $j^{\text {th }}$ input variable of the antecedent and the domain of $x$ in $X$, can be defined as $X=X_{1} \times X_{1} \times \ldots \times X_{n v}, X_{j} \subseteq \mathrm{R}$.

In particular, the Z-FRB structure can be expressed as follow, where the multi-dimensional antecedent fuzzy subset of $i^{\text {th }}$ rule is Ai. This multi-dimensional antecedent fuzzy subset determination eliminates the search for the appropriate $t$-norm for the combination of antecedent fuzzy subsets with "AND". Thus, variations of Z-FRB are Sugeno et al. [10], SY-FRB, and Takagi et al. [11] (TS-FRB) Fuzzy Rule Base structures:

(SY-FRB) $\quad R: A \underset{i=1}{c^{*}} S\left(\right.$ IF $x \in X$ isr $A_{i}$ THEN $\mathrm{y} \in Y$ isr $\left.B_{i}\right)$

(TS-FRB) $\quad R: A L S O$ (IF antecedent $_{i}$ THEN $y_{i}=a_{i} x^{T}+b_{i}$ )

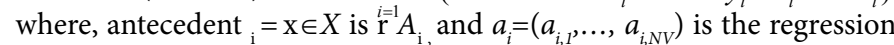


coefficient vector associated with the $i^{\text {th }}$ rule together with $b_{i}$ which is the scalar associated with the $i^{\text {th }}$ rule. For these special cases of Z-FRB, again each degree of firing, $d_{i}$, associated with the $-i^{\text {th }}$ rule, is determined directly from the corresponding $i^{\text {th }}$ multi-dimensional antecedent fuzzy subset $A_{i}$ and applied to the consequent fuzzy subset for the SY-FRB or to the classical ordinary regression for the case of TS-FRB.

\section{Fuzzy regression functions}

There are a number of variations of the proposed Fuzzy Regression Functions. We discuss here only one alternative in this paper, namely, Fuzzy Regression Functions which we have proposed with LSE.

Fuzzy regression functions with LSE (FF-LSE): In ordinary LSE (Least Square Estimation) method, the dependent variable, $y$, is assumed to be a linear function of input, variables, $x$, plus an error component:

$$
y=\beta_{0}+\beta_{1} x_{1}+\ldots+\beta_{n v} x_{n v}+\varepsilon
$$

where $y$ is the dependent output, $x_{i}$ 's are the explanatory variables input, for $j=1, \ldots, n v, n v$ is the number of selected inputs and $\varepsilon$ is the independent error term which is typically assumed to be normally distributed. The goal of the least squares method is to obtain estimates of the unknown parameters, $\beta$ 's, $j=0,1, \ldots, n v$, which indicate how a change in one of the independent variables affects the dependent variable.

$$
\beta=\left(\mathrm{X}^{\mathrm{T}} \mathrm{X}\right)^{-1} X^{T} y
$$

The proposed generalization of LSE as FF-LSE (Fuzzy Functions with LSE, more appropriately know as Fuzzy Regression Functions with LSE), requires that a fuzzy clustering algorithm, such as FCM, or IFC be available to determine the interactive (joint) membership values of input-output variables in each of the fuzzy clusters that can be identified for a given training data set. Let $\left(X_{k}, Y_{k}\right), k=1, \ldots, n d$, be the set of observations in a training data set, such that $X_{k}=\left(x_{j k} \mid j=1, \ldots\right.$, $n v)$. First, one determines the optimal $\left(m^{*}, c^{*}\right)$ pair for a particular performance measure, i.e., a cluster validity indeces such as Bezdek [4], and Celikyılmaz et al. [5] With an iterative search and an application of FCM or IFC algorithm, where $m$ is the level of fuzziness (in our experiments we usually take $m=1.4, \ldots, 2.5$ ), Ozkan et al. [12] and $c$ is the number of clusters (in our experiments we usually take $c=2, \ldots, 10$ ). The well-known FCM [4] algorithm can be stated as follows:

$$
\begin{array}{ll}
\text { s.t. } & 0 \leq u_{i k} \leq 1, \forall i, k \\
& \sum_{i=1}^{c} u_{i k}=1, \forall k \\
& 0 \leq \sum_{k=1}^{n d} u_{i k} \leq n d, \forall i
\end{array}
$$$$
\min \boldsymbol{J}(\boldsymbol{U}, \boldsymbol{V})=\sum_{k=1}^{n d} \sum_{i=1}^{c}\left(u_{i k}\right)^{m}\left(\left\|x_{k}-v_{i}\right\|\right)_{A}
$$

Where $J$ is objective function to be minimized, $\|.\|_{A}$ is a norm that specifies a distance based similarity between the data vector $x_{k}$ and a fuzzy cluster center $v$. In particular, $A=I$ is the Euclidian Norm and $A=C^{-1}$ is the Mahalonobis Norm, etc.

Once the optimal pair $\left(m^{*}, c^{*}\right)$ is determined with the application of FCM algorithm, and a cluster validity index one next identifies the cluster centers for $m=m^{\star}$ and $c=1, \ldots, c^{\star}$ as:

$$
v_{X \mid Y, j}=\left(x_{1, j}^{c}, x_{2, j}^{c}, \cdots, x_{n v, j}^{c}, y_{j}^{c}\right)
$$

From this, we identify the cluster centers of the input space again for $m=m^{\star}$ and $c=1, \ldots, c^{\star}$ as:

$$
v_{X, j}=\left(x_{1, j}{ }^{c}, x_{2, j}{ }^{c}, \cdots, x_{n v, j}{ }^{c}\right)
$$

Next, one computes the normalized membership values of each vector of observations in the training data set with the use of the cluster center values determined in the previous step. There are generally two steps in these 3 .

\section{Calculations}

First we determine the (local) optimum membership values $u_{i k}$ 's and then determine $\mu_{i k}$ 's that are above an $\alpha$ - cut in order to eliminate harmonics generated by FCM as:

$$
u_{i k}=\left(\sum_{j=1}^{c}\left(\frac{\left\|x_{k}-v_{X, i}\right\|}{\left\|x_{k}-v_{X, j}\right\|}\right)^{\frac{2}{m-1}}\right)^{-1}, \mu_{i k} \geq \alpha,
$$

where $\mu_{i k}$ denotes the membership value of the $k^{\text {th }}$ vector, $k=1, \ldots, n d$, in the $i^{\text {th }}$ rule, $i=1, \ldots, c^{*}$ and $x_{k}$ denotes the $k^{\text {th }}$ vector and for all the input variables $j=1, \ldots, n v$, in the input space. (2) Next, we normalize them as:

$$
\gamma_{i j}\left(x_{j}\right)=\frac{\mu_{i j}\left(x_{j}\right)}{\sum_{i^{\prime}=1}^{c} \mu_{i^{\prime} j}\left(x_{j}\right)}
$$

where $\gamma_{\mathrm{ij}}$ is the normalized membership value of $x_{j}, j=1, \ldots, n v$, in the $i^{\text {th }}$ rule, $i=1, \ldots, c^{*}$, which in turn will indicate the membership value that will constitute an new input variable in our proposed scheme of function identification for the representation of $i^{\text {th }}$ cluster. Let

$\Gamma_{i}=\left(\gamma_{i j} \mid i=1, \ldots, c^{*} ; j=1, \ldots, n v\right)$ be the membership values of $X$ in the $i^{\text {th }}$ cluster, i.e., rule.

Next we determine a new augmented input matrix $X$ for each of the clusters which could take on several forms depending on which transformations of membership values we want to or need to include in our system structure identification for our intended system analyses. Examples of these are:

$$
X_{i}^{\prime}=\left[1, \Gamma_{i}, X\right], X_{i}^{\prime \prime}=\left[1, \Gamma_{i}^{2}, X\right], X_{i}^{\prime \prime \prime}=\left[1, \Gamma_{i}^{2}, \Gamma_{i}^{m}, \exp \left(\Gamma_{i}\right), X\right] \text { etc, }
$$
where $X_{i}{ }^{\prime}, X_{i}{ }^{\prime}, X_{i}{ }^{\prime \prime}$ are the new input matrices to be used in least squares estimation of a new system structure identification where

$$
\Gamma_{i}=\left(\gamma_{i j} \mid i=1, \ldots, c^{*} ; j=1, \ldots, n v\right)
$$

The choice depends on whether we want to or need to include just the membership values or some of their transformations as new input variables in order to obtain a best representation of a system behavior. In particular, this is done in order to get a higher value of $\mathrm{R} 2$ to show that a better model is obtained for an application. A new augmented input matrix, say $X_{i}^{\prime}$, would look as shown below for the special case of $X=X_{j}$, i.e., the matrix $X$ is just a vector of a single variable, $X_{j}=\left(x_{j k} \mid\right.$ $\mathrm{k}=1, \ldots, n d$ ) for the $j^{\text {th }}$ variable:

$$
X_{i j}^{\prime}=\left[1, \Gamma_{i}, X_{i j}\right]=\left[\begin{array}{ccc}
1 & \gamma_{i 1} & x_{i j 1} \\
\vdots & \vdots & \vdots \\
1 & \gamma_{\text {ind }} & x_{i j n d}
\end{array}\right]
$$

Thus the fuzzy regression function, $Y_{i}=\beta_{i 0}+\beta_{i 1} \Gamma_{i}+\beta_{i 2} X_{i j}$, that represents the $\mathrm{i}_{\mathrm{th}}$ rule corresponding to the $\mathrm{i}_{\mathrm{th}}$ interactive (joint) cluster in space $\left(Y_{i}, \Gamma_{i}, X_{j}\right) \quad \beta_{i}^{*}=\left(X_{i j}{ }^{T} X_{i j}\right)^{-1}\left(X_{i j}{ }^{T} Y_{i}\right) \quad X_{i j}{ }^{\prime}=\left[1, \Gamma_{i}, X_{i j}\right]$ 


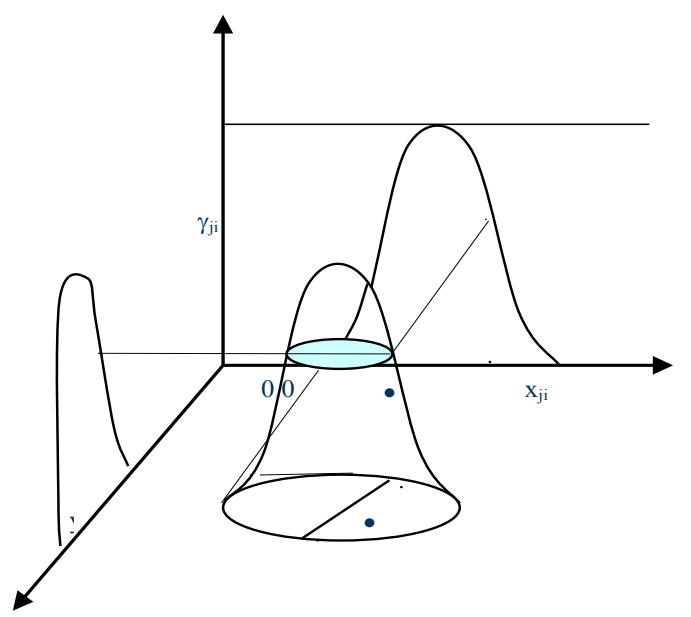

Figure 1: Fuzzy cluster in $U \times X \times Y$ space.

Such that $\beta_{i}{ }^{*}=\left(\beta_{i 0}{ }^{*}, \beta_{i 1}{ }^{*}, \beta_{i 2}{ }^{*}\right)$ and the estimate of $Y_{i}$ would be obtained as $Y_{i}^{*}=\beta_{i 0}^{*}+\beta_{i 1}^{*} \Gamma_{i}+\beta_{i 2}^{*} X_{i j}$

Within the proposed framework, the general form of the shape of a cluster can be conceptually captured by a second order (cone) in the space of $U_{x} X_{x} Y$ which can be illustrated with a prototype shown in Figure 1.

One usually determines Type 1 membership values with an application of FCM [...] algorithm shown below:

\section{Algorithm 3.1. Fuzzy c-means clustering algorithm (FCM)}

Given data vectors, $X=\left\{x_{1}, . ., x\right\}$, number of clusters, $c$, degree of fuzziness, $m$, and a termination constant, $\varepsilon$ (maximum iteration number in this case). Initialize the partition matrix, $U$, randomly.

Step 1. Find initial cluster centers using via equation 1 shown below using membership values of initial partition matrix as inputs.

Step 2. Start iteration $t=1 \ldots$ max-iteration value;

Step 2.1. Calculate membership values of each input data object $k$ in cluster $i, \mu_{i k}^{(t)}$, using the membership value calculation equation in via equ 1 below, where $x_{k}$ are input data objects as vectors and $v_{i}^{(t-1)}$ are cluster centers from $(t-1)^{\text {th }}$ iteration,

${ }_{(t)}$ Step 2.2. Calculate cluster center of each cluster $i$ at iteration $t$, $v_{i}^{(t)}$ using the cluster center function in equ 2 shown below, where the inputs are the input data matrix, $x_{k}$, and the membership values of iteration $t, \mu_{i k}^{(t)}$.

Step 2.3. Stop if termination condition satisfied, e.g.,

$\left|U_{i}^{(\mathrm{t})}-U_{i}^{(\mathrm{t}-1)}\right| \leq \varepsilon$ Otherwise go to step 1.

Where equation 1 stated in the algorithm above is:

$\mu_{i k}^{(t)}=\left[\sum_{j=1}^{c}\left(\frac{d\left(x_{k}, v_{i}^{(t-1)}\right)}{d\left(x_{k}, v_{j}^{(t-1)}\right)}\right)^{\frac{2}{m-1}}\right]^{-1}$

And equation 2 is:

$$
v_{i}^{(t)}=\left(\sum_{k=1}^{n}\left(\mu_{i k}^{(t)}\right)^{m} x_{k}\right) / \sum_{k=1}^{n}\left(\mu_{i k}^{(t)}\right)^{m}, \forall i=1, \ldots, c
$$

\section{Generation of Full Type 2 Membership Values}

For this purpose, we propose and hence introduce a new algorithm in order to generate Full Type 2 membership value distribution from the results obtained with an application of FCM which produce a Type 1 membership value distribution for our studies of Full Type 2 investigations.

\section{Full Type 2 fuzziness i.e., membership of membership}

Here we want to show how one determines the second order degree of fuzziness in order to develop Full Type 2 fuzzy system models.

It should be noted that depending on where $x \in X$ is there may be more than one second order membership value distribution.

\section{Full type 2 fuzzy set extraction algorithms}

We propose the following Full Type 2 fuzzy set extraction algorithm from a given data set called FT2FCM [13]

\section{Full type 2 fuzzy clustering algorithm}

$$
\begin{aligned}
& \operatorname{Min} J^{\prime}\left(\mathrm{U}^{\prime}(\mathrm{U}), \mathrm{W}\right)=\sum_{k=1}^{n d} \sum_{i=1}^{c^{\prime}} \sum_{l=0}^{1}\left(\mu_{\mu \mathrm{i}(\mathrm{xk})}(\mathrm{z})\right)\left(\| \mu_{\mu i(\mathrm{xk})}\left(\mathrm{z}_{1}\right)\right) \\
& \left.\operatorname{Min} J^{\prime}(\mathrm{U}(\mathrm{U}), \mathrm{W})=\sum_{k=1}^{n d} \sum_{i=1}^{c^{\prime}} \sum_{l-o}^{1}\left(\mu_{\mu \mathrm{i}(x k)}(\mathrm{z})\right)\left(\| \mu_{\mu \mathrm{i}(x k)}\left(z_{l}\right)\right)-\bar{\mu}(x k)\left(z_{l}\right) \| A\right), k=1, \ldots, n d ; \\
& i=1, \ldots, c^{\prime} \\
& \text { st. } 0 \leq \mu_{\mu i(x k)}(\mathrm{z}) \leq 1 \\
& 0 \leq \mu_{i}(x k) \leq 1 \\
& 0 \leq \sum_{k=1}^{n d} \mu_{i}\left(x_{k}\right) \leq n d \\
& \mu_{i}\left(x_{k}\right) \ni[0,1] ; \mu_{\mu_{i}\left(x_{k}\right)}(\mathrm{z}) \ni[0,1] ; l \ni[0,1]
\end{aligned}
$$

Where $J$ ' is the objective function to be minimized for a given $x_{k} \in X,\|\|$.$A is a norm, i.e., Euclidian or Mahalanobis, that specifies a$ distance measure based on a membership values for a given $x_{k} \in X$ and its second order fuzzy cluster center $\bar{\mu}_{i}\left(x_{k}\right)$.

Next one computes the normalized membership values of these Full Type 2 membership values for each vector of membership values obtained in an initial application of the original FCM or IFC algorithm in the first stage.

There are generally two steps in these calculations:

We first determine (local) optimum membership of membership values $\mu_{\mu \mathrm{i}}\left(x_{k}\right)$ 's and then apply an $\alpha$-cut in order to eliminate the second order harmonics generated by an application of FT2FCM as:

$$
\begin{gathered}
\mu_{x_{k i} \in X}\left(x_{k}\right)=\left[\left(\sum_{i=1}^{c^{\prime}} \frac{\left\|\mu_{\mu i}\left(x_{k}\right)-\bar{\mu}_{i}\left(x_{k}\right)\right\|}{\left\|\mu_{\mu i}\left(x_{k}\right)-\bar{\mu}_{j}\left(x_{k}\right)\right\|}\right)^{\frac{2}{m-1}}\right]^{-1} \\
\mu_{\mu i}\left(x_{k}\right) \geq \alpha \\
\gamma^{\prime} \mu_{\mu i}\left(x_{k}\right)=\frac{\mu_{\mu i}\left(x_{k}\right) \mid x_{k} \in X}{\sum_{i=1}^{c^{\prime}} \mu_{\mu i}\left(x_{k}\right)}
\end{gathered}
$$


Citation: Türkşen IB (2014) From Hierarchy of the Levels of Theoretical Inquiry to Full Type 2 Fuzzy System Models. Ind Eng Manage 3: 133. doi: 10.4172/2169-0316.1000133

Page 5 of 7

$$
\gamma^{\prime} \mu_{\mu i}\left(x_{k}\right) \geq \alpha
$$

Where $\gamma^{\prime} \mu_{\mu i}\left(x_{k}\right)$ denotes the membership values of the membership values of the $k_{\text {th }}$ vector $k=1, . ., n d$ in the $i_{\text {th }}$ rule, or $i_{\text {th }}$ fuzzy regression function $[14,15]$ and $x_{k} \in X$ denotes the $k_{\text {th }}$ vector and for all the input variables, $k=1, . ., n d$ in the input space.

Recall that we are able to obtain the membership value distribution as:

$$
\begin{aligned}
& X_{i j}^{\prime}=\left[1, \Gamma_{i}, X_{i j}\right]=\left[\begin{array}{ccc}
1 & \gamma_{i 1} & x_{i 1} \\
\vdots & \vdots & \vdots \\
1 & \gamma_{\text {ind }} & x_{i n d}
\end{array}\right] \\
& \Gamma_{i}=\left(\gamma_{i k} \mid i=1, \ldots, c^{*} ; k=1, \ldots, n d\right) \\
& \Gamma_{i}=\left(\gamma_{i j} \mid i=1, \ldots, c^{*} ; j=1, \ldots, n d\right) \quad \Gamma_{i}=\left[\begin{array}{cccc}
\gamma_{11} & \gamma_{21} & \cdots & \gamma_{c^{*} 1} \\
\vdots & \vdots & & \vdots \\
\gamma_{1 n d} & \gamma_{2 n d} & \cdots & \gamma_{c^{*} n d}
\end{array}\right]
\end{aligned}
$$

We process each $\Gamma_{i}$ via our Full Type 2 clustering algorithm given above, called FT2FCM, to determine Full Type 2 distribution for each cluster $i, \Gamma_{i}=\left(\gamma_{i j} \mid i=1, \ldots, c^{*} ; j=1, \ldots, n d\right)$

Thus we apply to each $\Gamma_{i}$, Algorithm 2 given below to generate Full Type 2 membership, values, i.e., membership of membership.

\section{Algorithm 2. Full Type 2 Fuzzy c-means Clustering Algorithm (FT2FCM)}

Given data vectors,

$\Gamma_{i}=\left(\gamma_{i j} \mid i=1, \ldots, c^{*} ; j=1, \ldots, n d\right)$, number of clusters, $c^{\prime}$, degree of fuzziness, $m$, and termination constant, $\varepsilon$ (maximum iteration number in this case). Initialize a partition matrix, $\Gamma$, randomly.

Step 1. Find initial cluster centers using via equation 3 shown below using membership of membership values of initial partition matrix as inputs.

Step 2. Start iteration $t=1 \ldots$ max-iteration value;

Step 2.1. Calculate Type 2 membership values of a given , $\Gamma$ vector of each input data object $k$ in cluster $i, \mu_{\mu i}(x k)$, using each $\Gamma$ vector of the membership values where $x_{k}$ are input data objects as vectors and $\bar{\mu}_{i}\left(x_{k}\right)$ are Type 2 cluster centers from $(t-1)^{\text {th }}$ iteration.

Step 2.2. Calculate Type 2 cluster center $w_{i k}$ of each cluster $l$ at iteration $t$, the $\mathrm{t}$-th $\bar{\mu}_{i}\left(x_{k}\right)$ he cluster center function of Type 2 membership values in equation 4 shown below, where the inputs are the input data matrix, and the membership of the membership values of iteration $t, \mu_{\mu_{i}}\left(x_{k, \mathrm{t}}\right)$

Step 2.3. Stop if termination condition satisfied, e.g

Otherwise go to step 1.

\section{Experimental Results}

We present here our experimental results for TD_Stock Price Data set that is available for all researchers on the internet.

Çelikyılmaz-Türkşen's validity index results for TD_Stockprice data figures 2-13.

\section{Results and Conclusion}

In this paper, we have first review the essentials fuzzy system models: such as (1) Zadeh's rule base model, (2) Takagi and Surgeon's partly a rule base and partly a regression function model and (3) Türkşen`s "Fuzzy Regression Functions" model where a fuzzy regression function correspond to each fuzzy rule and thus a fuzzy rule base is replaced with "Fuzzy Regression Functions" model. Next we review the wellknown FCM algorithm which lets one to extract Type 1 membership values from a given data set for the development of "Type 1" fuzzy system models as a foundation for the development of "Full Type 2" fuzzy system models. For this purpose, we provide an algorithm which

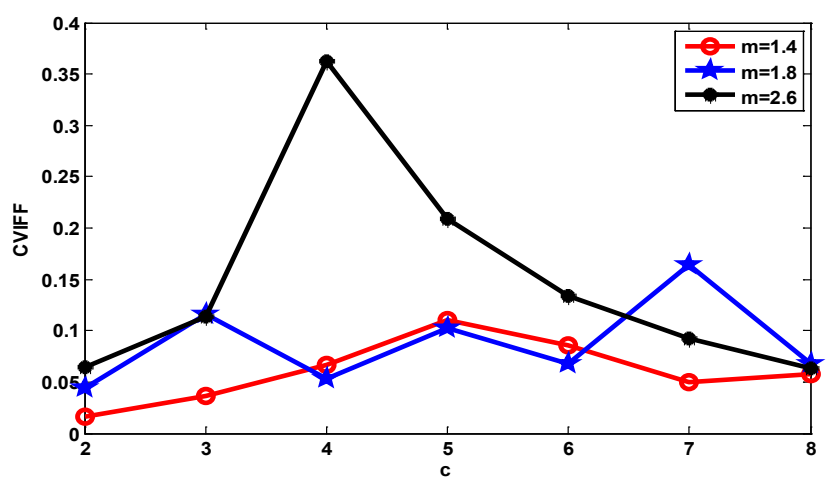

Figure 2: Fuzzy classification of TD_Stockprice data: $\left(c^{*}=2, m^{*}=1.8\right)$.

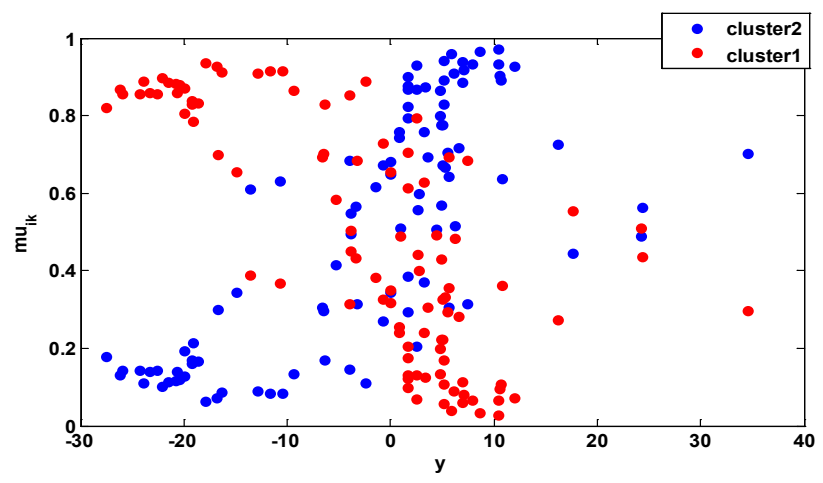

Figure 3: Cluster-2 view for TD_Stockprice data

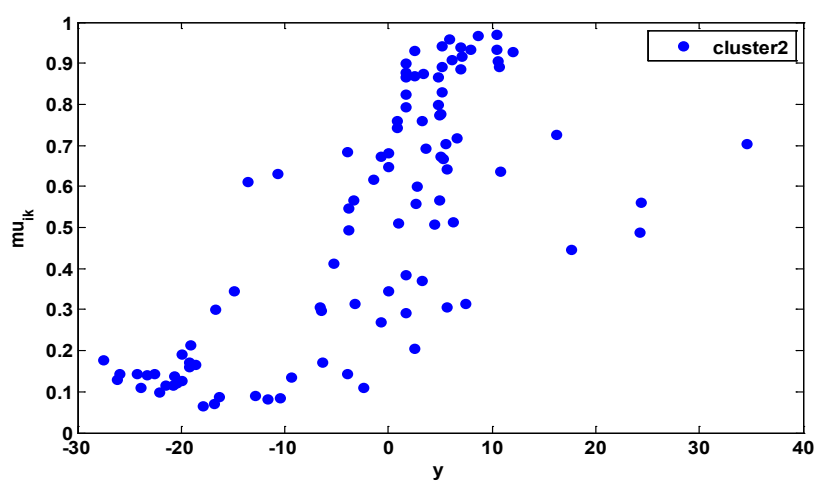

Figure 4: Çelikyılmaz-Türkşen's Validity Index for $\mu_{\mathrm{ik}}$ dat. 


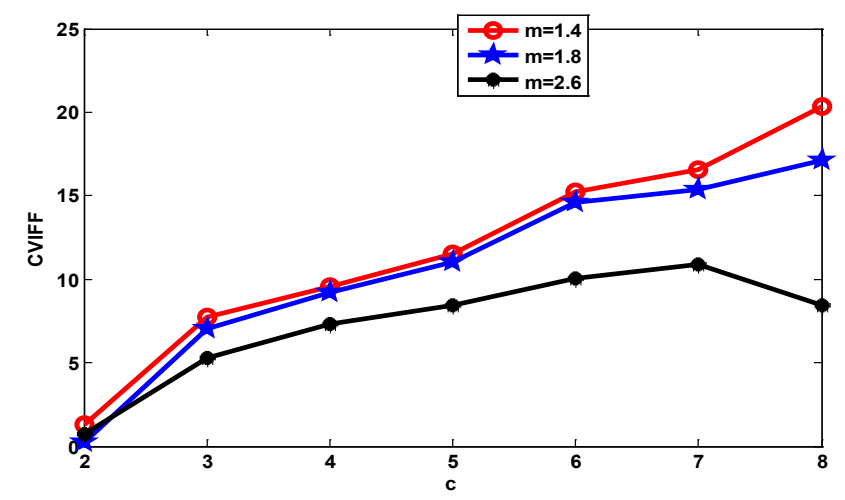

Figure 5: Cluster-2 results of TD-Stockprice data $\left(\mathrm{c}^{*}=2, \mathrm{~m}^{*}=1.8\right)$. cv.

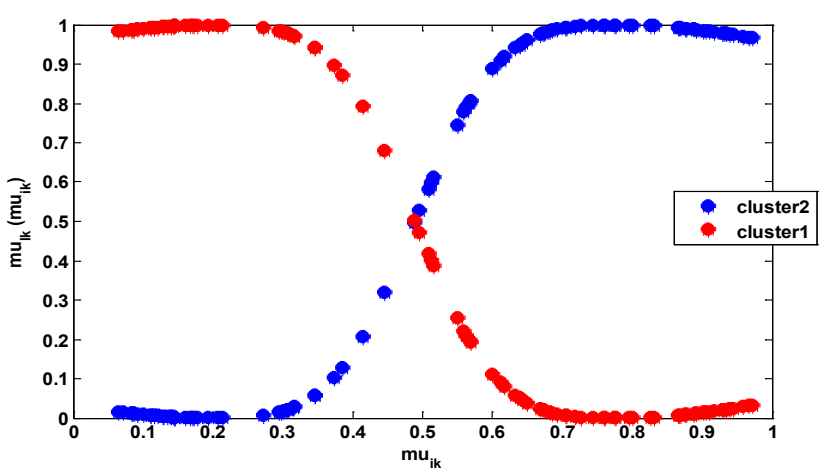

Figure 6: $\mu_{i k}\left(\mu_{i k}\right)$ for Cluster1 and 2 are shown above.

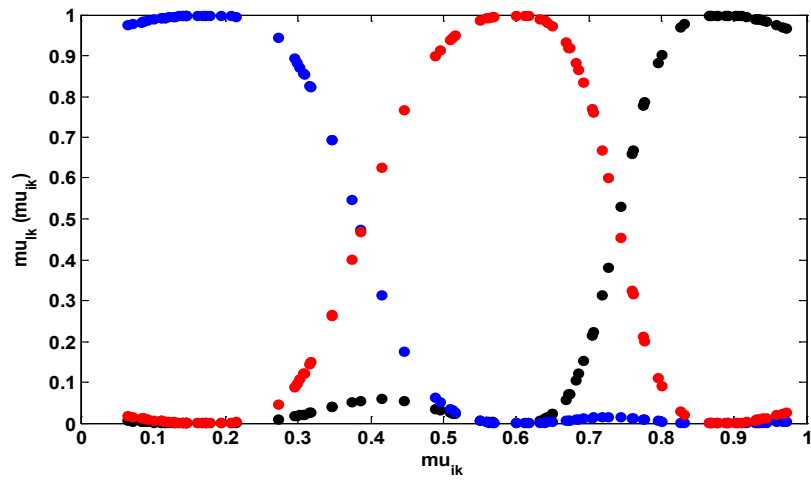

Figure 7: A possible three cluster view.

lets one to generate Full Type 2 membership value distributions for a development of second order fuzzy system models with our proposed second order data analysis. If required one can generate Full Type 3, Full Type $\mathrm{n}$ fuzzy system models with an iterative execution of our algorithm. Finally we present our results graphically for TD_Stockprice data with respect to two validity indeces, namely: 1) ÇelikyllmazTürkşen and 2) Bezdek indeces. Based on our development, we expect in the future new results would be obtained in "Full Type 3, Full Type n" fuzzy system model analyses.

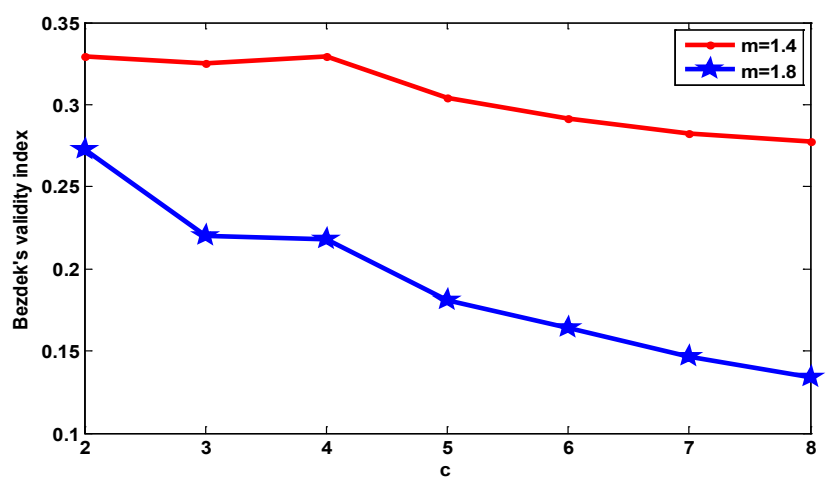

Figure 8: Fuzzy classification of TD_Stockprice data: $\left(c^{*}=3, m^{*}=2.0\right)$.

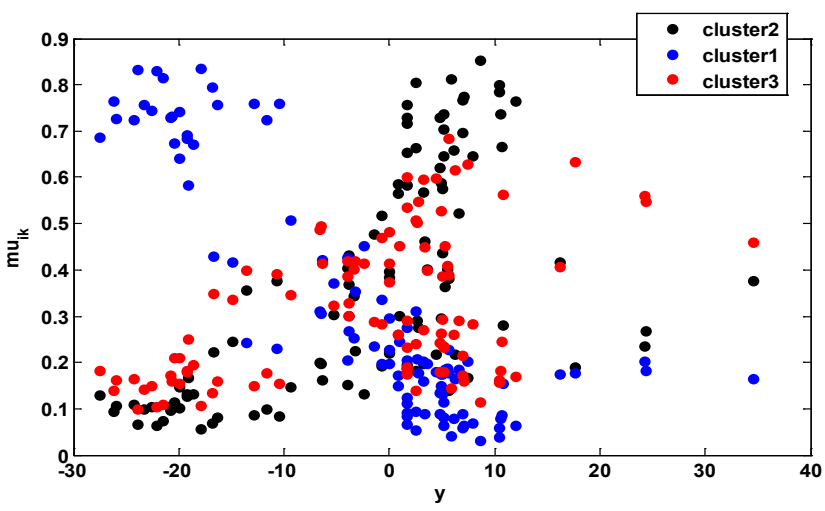

Figure 9: Cluster-2 view for TD_Stockprice data.

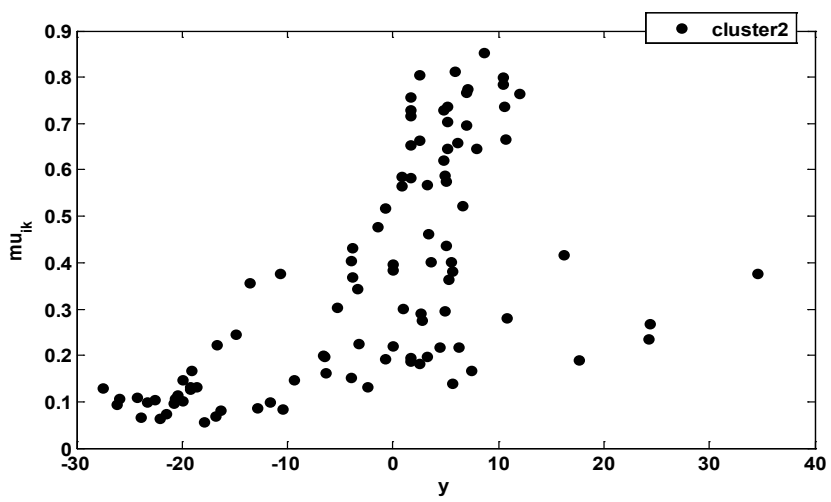

Figure 10: Çelikyılmaz-Türkşen's Validity Index for $\mu_{\mathrm{ik}}$ data.

\section{References}

1. Zadeh LA (1965) Fuzzy sets. Inform Control 8: 338-353.

2. Turksen IB (2006) An Ontological and Epistemological Perspective of Fuzzy Set Theory. Elsevier USA.

3. Türkşen IB (2002) Type 2 representation and reasoning for CWW. Fuzzy Set Syst 127: 17-36.

4. Bezdek JC (1981) Pattern Recognition with Fuzzy Objective Function Algorithms. Plenum Press New York USA.

5. Celikyilmaz A, Türkşen IB (2008) Validation criteria for enhanced fuzzy clustering. Pattern Recogn Lett 29: 97-108. 
Citation: Türkşen IB (2014) From Hierarchy of the Levels of Theoretical Inquiry to Full Type 2 Fuzzy System Models. Ind Eng Manage 3: 133. doi: 10.4172/2169-0316.1000133

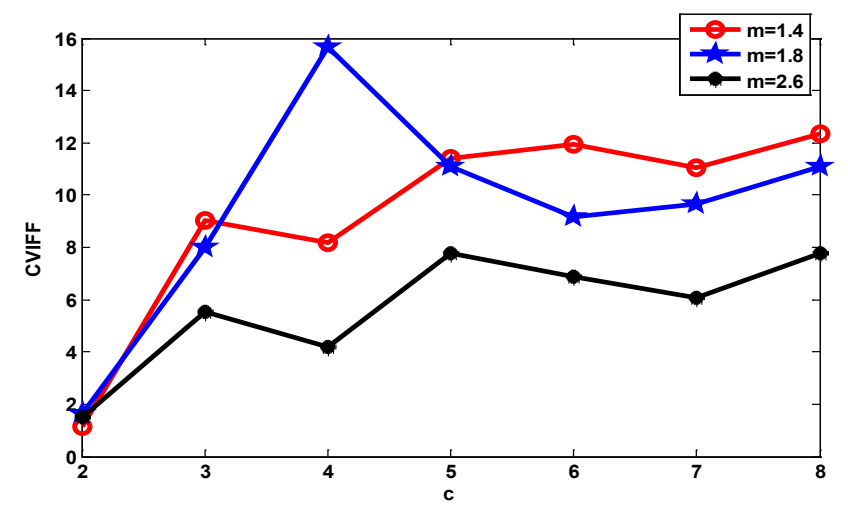

Figure 11: Cluster-2 results of TD-Stockprice data $\left(\mathrm{c}^{*}=3, \mathrm{~m}^{*}=2.0\right)$ for membership of membership.

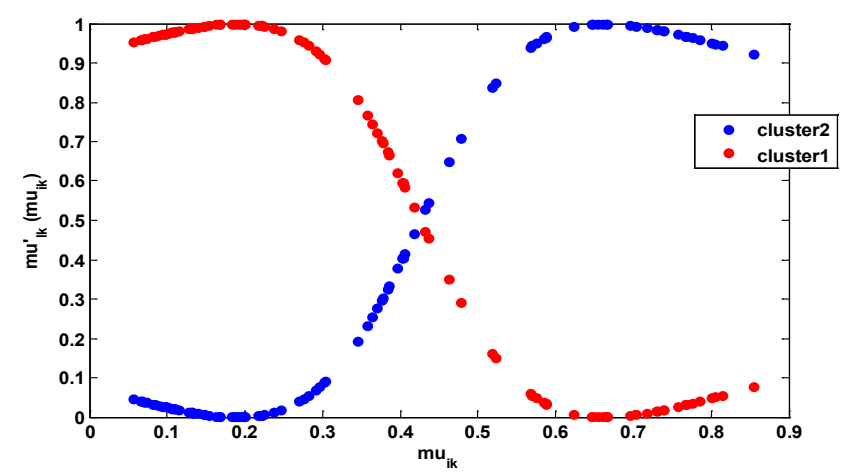

Figure 12: A possible three cluster view.

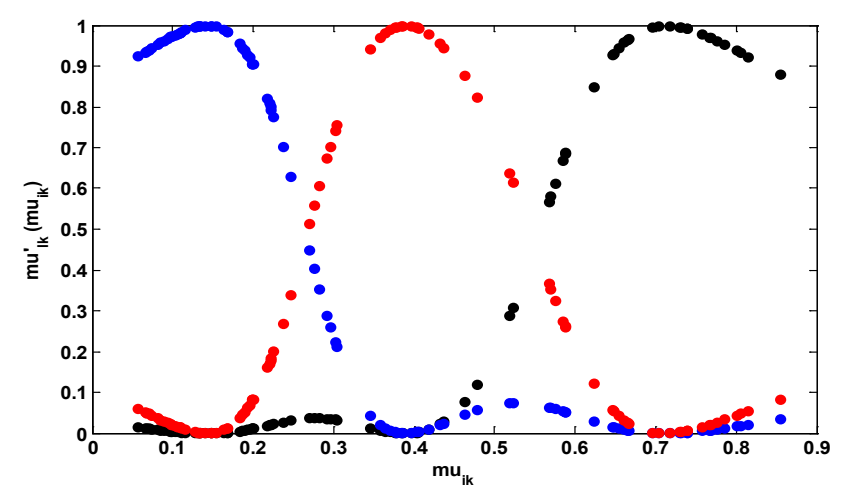

Figure 13: A possible three cluster view.
6. Zadeh LA (1975) The concept of a linguistic variable and its application to approximate reasoning-I. Inform Sciences 8: 199-249.

7. Zadeh LA (1975) The concept of a linguistic variable and its application to approximate reasoning-II. Inform Sciences 8: 301-357.

8. Zadeh LA (1975) The Concept of a Linguistic Variable and its Application to Approximate Reasoning-III Inform Sciences 9: 43-80.

9. Ebrahim MH (1977) Application of Fuzzy Logic to Approximate Reasoning Using Linguistic Synthesis. IEEE T Comput C-26: 1182-1191.

10. Sugeno M, Yasukawa T (1993) A fuzzy-logic-based approach to qualitative modeling. IEEE T Fuzzy Syst 1.

11. Takagi T, Sugeno M (1985) Fuzzy identification of systems and its applications to modeling and control. IEEE T Syst Man Cyb SMC-15: 116-132.

12. Ozkan I, Turksen IB (2007) Upper and lower values for the level of fuzziness in FCM. Inform Sciences 177: 5143-5152.

13. Türkşen IB (1996) Non-specificity and interval-valued fuzzy sets. Fuzzy Set Syst 80: 87-100.

14. Türkşen IB (2007) Meta-linguistic axioms as a foundation for computing with words. Inform Sciences 177: 332-359.

15. Türkşen IB (2008) Fuzzy functions with LSE. Applied Soft Computing 8: 11781188. 